\title{
The challenge of contributing to policy making in primary care: the gendered experiences and strategies of nurses
}

\section{Alison Hughes}

\section{School of Health and Social Care, University of the West of England, Bristol}

\begin{abstract}
This paper explores nurses' experiences as members of primary care organisations set up to develop and commission health services for local communities. Nurses, alongside GPs and other health professionals, were given a place on the governing bodies (boards) of Local Health Groups (***?in Wales) - a move widely welcomed by the nursing profession as long overdue recognition of the important contribution nurses and nursing could bring to the policy arena. Nurse board members faced a number of challenges in their attempts to contribute to and influence local health policy. This ethnographic study (which involved nonparticipant observation of 33 board meetings and interviews with 29 board members including nurses) suggests that medical authority and control, and hierarchical power relations between doctors and nurses on the board, were seen by nurses as significant obstacles to their participation in this new policy arena. In response to their perceived lack of power and subordinate status, nurses employed a number of strategies to negotiate their participation as board members - these included 'getting it right', 'achieving the right balance', 'selfpresentation' and 'unassertiveness'. These strategies reflected and re-produced gendered identities and relations of power and raise important questions regarding the influence of nurses and nursing within policy making.
\end{abstract}

Keywords: gender, Local Health Group, doctor/nurse relationships, policy, nurses, nursing identity, ethnography.

\section{Introduction}

This paper explores the experiences of nurses working within the policy-making arena. Particular attention is given to the role of gender and nursing identity and the strategies used by nurses to manage and negotiate hierarchical relations as board members of Local Health Groups (??in Wales) - a key forum for policy making in the field of primary care.

The establishment of Local Health Groups in 1999 marked a critical time for the National Health Service (NHS). The newly elected Labour government put primary care at the centre of health policy modernisation, and instigated a major reform of the organisation of primary care throughout the UK (Exworthy 2001). In particular, the government White Papers Putting Patients First (Welsh Office 1998a) and The New NHS: Modern, Dependable (Department of Health 1997) proposed that existing models of health care commissioning be

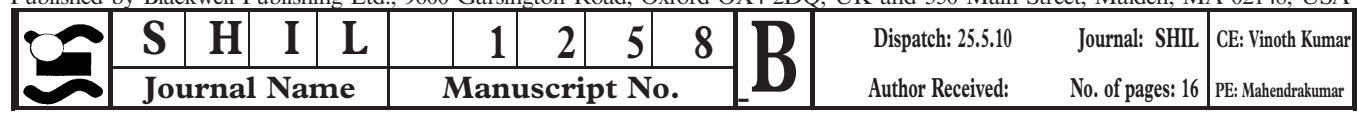


abolished and replaced with Local Health Groups (LHGs) in Wales, and in England, Primary Care Groups (PCGs).

This was part of a policy drive for a more collaborative and integrated model of commissioning - a significant departure from previous commissioning organisations which were largely the preserve of general practitioners (GPs) (Smith, 2000).

Each LHG had a governing body - or 'board' - on which nurses were identified as having a key leadership role (Welsh Office 1998b, DoH 1997, Regen et al. 2001). The boards brought together representatives (up to 18) from a range of health and social care providers and users - nurses, doctors (including GPs), a pharmacist, optometrist, dentist, members from the lay and voluntary sector, and representatives from the Local Authority and Health Authority. Working in partnership and pooling their knowledge and expertise, board members were expected to identify local health needs in consultation with local people and to develop and commission services to meet those needs. Board members, whilst continuing with their day-to-day work, attended monthly board meetings as well as various subcommittees focused on different aspects of LHG work (e.g. clinical governance, finance).

The appointment of nurses ${ }^{1}$ to the boards of LHGs presented nurses with a unique opportunity to influence health care policy (Antrobus 1998, RCN 1999, Smith et al. 1999). Various studies had emphasised the potential value of nurses to the commissioning process (Kings Fund College 1993, Department of Health 1994), and this development was viewed by many as a long overdue response to nursing's invisibility and exclusion from the policymaking arena (Antrobus 1998, RCN 1999, Kaufman 2002). At the time, expectations with regard to nurse involvement appeared high, as the then government Minister of Health commented in relation to Primary Care Groups:

By giving ... nurses a formal place on primary care group boards, the White Paper signals recognition of the contribution nurses can make to improving healthcare... in the new NHS nurses views will be heard and valued (cited in Mayor 1998: 578).

However, the opportunity for nurses to participate in decision making, and to influence policy, needs to be viewed in a critical light. Given the devalued status of nursing work and nursing's historical subordination within healthcare (Gamarnikow 1978, Reverby 1987, Robinson 1992, Davies 1995), questions remained as to the extent to which nurses would be able to take their place in the policy-making arena as equal partners and collaborators. In addition, board membership was predominately male, with strong representation from the medical profession - typically boards included two nurse members (usually female) and up to seven GPs (mostly male).

***?Welsh Local Health Groups and their English counterparts, Primary Care Groups were superseded in 2002/3 by Local Heath Boards and Primary Care Trusts respectively. Primary care continues to be a focus for reform and re-organisation (DoH 2008, WAG 2008), offering new opportunities and roles for nurses. The participation and involvement of nurses at a strategic and policy-making level within primary care (and the NHS as a whole) remains an area of interest and concern (QNI 2006, RCN/National Voices 2009); despite this, the role and experiences of nurses in policy making remains under researched (Drennan 2005).

This paper draws on feminist theory, in particular literature on gender and organisation (e.g. Acker 1992, Gherardi 1995, Davies 1995) to examine nurses' experiences on LHGs, and, more broadly, the gendering of organisational culture and the specific challenges this presents for nurses and nursing. 


\section{Gender and organisations}

Much of the literature which has directly explored the relationship between gender and work focuses on issues such as pay differentials, equal opportunities, and the sexual division of labour (Davies 1995). Whilst important in highlighting the discrimination facing women, these analyses do not adequately account for the difficulties in overcoming discriminatory practices, or for the 'apparently endless reorganisation of gender and permutations of male power' (Acker 1992:248).

Recently, a more radical shift in conceptualising these processes, and the relationship between gender and organisations, has emerged. Rather than seeing organisations as static, gender neutral spaces, gendered organisational analyses highlight the way in which organisations reflect, and actively construct and maintain, gendered subjectivities and power relations, through a complex interplay of various processes and interactions (Mills and Tancred 1992). Implicit in this is the concept of gender as a social dynamic, actualised through interaction. Gender is seen as 'a routine, methodical and recurring accomplishment' (West and Zimmerman 1991:14).

In this study a key element influencing the organisational experiences of nurses was the inter-professional relationship between medicine and nursing. This has been the subject of a wide range of nursing and sociological literature, and work by Gamarnikow (1978), Reverby (1987), Porter (1995), Davies (1995), Wicks (1998) and Davies (2003) exploits a variety of theoretical perspectives to highlight the central role of gender in shaping nurses' experiences, including their work relationship with doctors. Whilst acknowledging changes in the hierarchical nature of this relationship, there is also recognition that 'gendered relations and practices still hold sway in both traditional and new forms' (Davies 2003:737).

Recent studies of the relationship between medicine and nursing have drawn on the negotiated order perspective - for example, Svensson (1996) analyses doctor/nurse interaction in a Swedish hospital; Allen $(1997,2001)$ has explored the construction of the nursing/medical boundary in UK hospitals; and Speed and Luker (2006) utilised Foucault's theory of power to explore work relations between GPs and district nurses in primary care. These authors highlight the way in which relations between doctors and nurses are negotiated and constructed through social interaction, and provide much insight into the different ways in which medical dominance is resisted and re-produced in the clinical encounter.

However, whilst gender is not absent from these analyses, it is not given close and detailed consideration. For example, Svensson (1996) argues that there has been a shift in power relations between doctors and nurses, with nurses exerting increased influence. Yet his analysis suggesting nurses negotiate a more collaborative relationship, underplays the way in which this process reflects and perpetuates prevailing gender power relations and identities.

This paper builds on and adds to the existing literature in a number of ways. In drawing on gendered organisational theory and analysing nurses' experiences through the lens of gender, this paper highlights the way various social processes and interactions reflect and re-produce gender power relations and identities at an individual, organisational and structural level. In addition, much of the work exploring the inter-professional relationship between doctors and nurses has tended to focus on the clinical domain. This paper explores nurses' experiences in the policy- making domain. Particular attention is given to the way in which nurses managed their identity in the context of hierarchical gender power relations and within an organisational culture in which they perceived themselves as occupying a marginal and devalued position. The strategies nurses employed to manage their identity as women and nurses, and to negotiate their membership as credible board members, are explored. Drawing 
particularly on the work of Acker (1991, 1992) and Gherardi (1994, 1995) this paper highlights the way such gender management contributes to the gendering of organisational culture through the 'internal mental work' (Acker 1992: 253) of nurses as they make sense of the gendered structures, opportunities and rules governing organisational behaviour, and act accordingly - 'creating the correct gendered persona' (1992:253).

\section{Methodology}

The paper derives from a larger ethnographic study (Hughes 2005) which explored the ways in which gender shaped and impacted upon the organisational lives of nurses on LHG boards $(n=7)$. Data collection included non-participant observation of LHG board meetings $(n=33)$ and in-depth interviews with board members $(n=29)$ in their first and third (final) years of membership.

The study drew on an ethnographic approach (Hammersley and Atkinson 1995, Brewer 2000) and was underpinned by a feminist methodology (Maynard and Purvis 1994). The study was concerned with exploring women's experiences, the nature of gender power relations, and how these relations are (re) produced and impact on women (and men). Research questions centred on the ways in which gender power relations constitute nurses' organisational lives. Feminist theories were used to analyse and interpret research findings.

There were two phases of fieldwork: an initial period of nine months and then six further months following an 18-month interval. This was to ensure that nurses and board members were observed and interviewed in their first and their third (final) year as board members.

My sampling strategy reflected the logic and rationale of purposive sampling (Mays and Pope 1995) - I selected participants on the basis that they were able to shed light on the research topic. From the 44 LHG board nurses in Wales, I approached 12 nurses from five LHGs. These nurses were selected because a key informant (a senior nurse for primary care) was well known to them and was able to facilitate access. There were also pragmatic reasons (limited resources and travel considerations) for recruiting nurses from these five LHGs (Strauss and Corbin 1998).

To extend the sample to include board members from other geographic locations, attendance at various networking events associated with LHGs provided access to a further three nurse board members from two other LHGs, all of whom agreed to participate in the study. My sample therefore included 15 nurses who were members of seven LHGs. These LHGs then provided the setting for observation of board meetings and the subsequent recruitment of other board members. The LHGs covered urban, semi-rural and rural areas of Wales and varied in size in terms of the population served.

In total, in-depth interviews $(n=29)$ were conducted with 15 nurses, five GPs and three LHG managers (six of the nurse participants were re-interviewed during the second phase of data collection). The nurses interviewed were all qualified nurses, midwives or health visitors working in primary and community care with a minimum of 10 years post-qualification experience. Fourteen were female, one was male. They were aged between 30 and 55 years. Four of the five GPs were male. All the participants were White British. Interviews were tape recorded and transcribed verbatim.

Data collection also included non-participant observation of 33 board and sub-committee meetings (each lasting between one and three hours). Brief notes taken during periods of observation were later (within one or two days) worked up into more detailed fieldnotes (Lofland and Lofland 1984). In total the 70 hours of observation generated 56,000 words of fieldnotes. Fieldnotes consisted of observations 'at the lowest level of inference' (Lofland and 
Lofland 1984: 65) combined with methodological and analytic reflections and thoughts (Bogdewic 1992) including questions, emerging themes, and theoretical links to literature or previous observations.

The main thematic categories underpinning the observation and the interview topic guide included: working as a group, decision making, the nursing contribution, gender, and training and support. Using these broad themes, questions explored the ways in which nurses themselves made sense of and interpreted their experiences as board members.

All data were analysed thematically. Following a close reading of fieldnotes and interview transcripts, data were coded, and then grouped or collapsed into categories and then broader themes (Coffey and Atkinson 1996). The three main themes to emerge from the data analysis were: nursing identity, the nursing contribution, and medical power. This paper draws on those findings primarily relating to medical power, in particular the processes whereby gender power relations - including the doctor/nurse relationship - operated at board level.

The rigour of the research was maximised in a number of ways. Using a combination of data collection methods (interview, observation, and informal discussion during fieldwork) allowed testing of emerging themes and understandings, which provided further insight. For example, talking to nurses about their experiences of attending board meetings, then subsequently observing these meetings, was helpful in illuminating some of the issues nurses raised, as well as highlighting others they had not mentioned.

In addition, the study contains a reflexive account of the research process (Stanley and Wise 1993, Williams 1993) including the problems encountered, and how in turn these influenced the research (Brewer 2000). A detailed account of the process and strategies of data analysis and interpretation is provided (Maynard and Purvis 1994) as are lengthy extracts of data (fieldnotes and interviews) which allow the reader to judge the interpretation (Brewer 2000).

Ethical approval was granted by the relevant University and Health Authority Ethics committees. All participants were sent an outline of the research and told they could withdraw at any time. Participants signed a consent form prior to being interviewed and were assured that whilst data collected from the interviews and observation might be published, neither their names nor those of the LHGs would be identified. Following interview they were given the opportunity to comment on their interview transcripts. Five participants did so; their comments were to confirm they were happy with the transcript and on three occasions, to clarify some of their responses. Pseudonyms have been used for all participants.

\section{Findings}

Nurses described facing a number of important challenges as board members. In particular, they believed their ability to influence policy decisions and contribute to the work of the LHG had been circumscribed by the greater value placed on the interests and expertise of GPs. In response, they described a number of strategies they adopted to deal with and negotiate medical authority and control, and to manage their lack of credibility and feelings of powerlessness as nurse board members. These strategies call upon and re-produce gender identities and relations and illustrate one of the ways in which organisations are gendered.

\section{The view from below: nurses' accounts of medical dominance}

The issue of medical dominance (and nurses' relative lack of influence as board members) has been highlighted by a number of studies reporting on the progress of Primary Care Groups in England (Regen et al 2001, Dowsell et al. 2002, Drennan 2005). 
In this paper, medical dominance was described within the nurses' accounts in two overlapping ways. First, the way in which nurses believed GPs and their concerns fundamentally shaped and underpinned board activity, and limited the potential for alternative discourses such as a more social (rather than bio-medical) model of health with which these nurses more closely identified. Nurses also highlighted what they perceived as GPs' insularity, the privileging of medical knowledge and expertise on the board, and GPs' professional unity and lack of collaborative working.

Secondly, nurses referred to the inter-professional relationship between doctors and nurses, which reflected, and on occasions reinforced, medical authority and control. Their accounts of this relationship form the basis of this paper.

\section{Feelings of inadequacy and powerlessness}

A consistent theme in nurses' accounts was a belief that traditional hierarchical power relations between doctors and nurses still dominated. In particular, they highlighted the impact they believed this relationship was having on their ability to contribute to policy making within the LHG. Underpinning their accounts were feelings of inadequacy and powerlessness. For example, Maxine, an experienced health visitor, commented:

I hate to admit this after all these years but the 'doctor/nurse' baggage is still there. There is still this deference. I don't know why really. I felt overawed by the GPs - they are vocal and there are some good GPs on the group - they are well read and bright, but they have a narrow view of things. It stops you challenging - unless you are absolutely sure. It's hard to stick to your opinion. You think 'they must know' (Maxine).

As other nurses also argued, Maxine felt her training and socialisation as a nurse had left her with a legacy of deference and a lack of self-belief, which she felt other non-GP board members did not share. The 'baggage' to which Maxine referred was experienced as inhibiting. Despite believing that the medical view expressed at the board was at times narrow and ill informed, Maxine did not challenge this.

Observations of board meetings supported Maxine's view. GPs tended to be the most vocal members of the board and discussions predominately centred on GP concerns and interests (these issues often related to the business concerns of General Practice). I also noted nurses' reticence and apparent reluctance to challenge. The following notes are taken from a board meeting where the debate was dominated by a small number of GPs; other board members, including nurses, said very little:

Two hours into the board meeting with 14 people present - the same four people are doing most of the talking: two male GP board members who are the most vocal during this meeting, plus the GP Chair (male) and the General Manager (male), both of whom seem to be fielding questions/objections from the two GP board members. The two nurse members haven't said anything since the meeting began. Despite the Chair's attempts to move the agenda along there are constant challenges from the two GP board members. The rest of the board members are looking very tired and weary and appear to be bystanders. No one challenges the process. On leaving the meeting I feel frustrated and disappointed (Fieldnotes: LHG 1 board meeting, phase 2).

The legacy of the doctor/nurse relationship was something others also appeared to struggle with. Megan, a district nurse, commented that she was aware of the 'baggage' of the doctor/nurse relationship 'the whole time', but that as a board member she recognised it was 
necessary 'to put the baggage to one side'. This 'exorcism', as she described it, was 'up to her'. However, for some, managing feelings of inadequacy and inferiority in this setting was a particularly difficult task, and the inequalities inherent in this relationship proved hard to reconcile, as the following comment from Viv - a practice nurse - suggests:

It's a bit of a struggle I think probably because I want the GPs to realise - because the other members of the group don't give me a problem at all - I want them to know that I am their equal and perhaps I'm having a bit of a struggle with that at the moment... (Viv).

Viv realises that in terms of equality it is her relationship with GPs, rather than other disciplines within the board, that is so crucial. As others also reported, Viv works hard to manage the negative feelings and emotions she experiences in response to the felt inequalities of the doctor/nurse relationship.

\section{Gender relations at work}

These nurses' accounts also draw attention to the gendered underpinnings of the doctor/nurse relationship and in particular the way in which day-to-day interactions and rituals reflected and maintained the hierarchical gender power relations between them. For example, Sarah, a practice nurse, highlighted the significance of her identity as a woman both on the board, and in her relationship with one of the male, medical board members:

You are down to being quite outnumbered, you know, and on all the sub-groups I am the only female. ... I end up pouring the coffee ... I think 'Why am I doing this?' You know? I always get there first, that's the problem, and I have to pour the coffee and I think, 'You mad fool'. I will stop that; I'm not going to do that.

It's a hard habit to break, you know ... I am just thinking about all the daft things I do, you know, like taking the clingfilm off the sandwiches - but then again Dr Wilson will give me the plate...

It's this two-fold thing - I know I shouldn't do it, but I'm comfortable doing it. ... I didn't think about it before until this interview, you know, that I've got to stop being this submissive female (Sarah).

In making coffee and assisting Dr Wilson, Sarah acknowledges that she conforms to and reproduces a role stereotypically ascribed to women. Sarah's role as hostess provides her with a strategy for gaining approval and power. The strategy she uses is gendered - serving and servicing the needs of others - something she finds reassuring and comfortable (see for example Graham 1983), but as she is aware, it also risks undermining her credibility. She reconfirms her identity as a 'submissive female'.

Whilst Sarah is keen to reject this identity, her account also illustrates the pleasures involved in conforming to gendered roles (being object to his subject). Rejecting such gendered norms of behaviour and asserting a more autonomous identity as a nurse and woman 'means losing identification with the overvalued part of the system' (Kerr 1982:304) and with it the power (and pleasure) that such an alliance affords. This is perhaps the difficulty facing Sarah (and nurses/nursing in general) and illustrates the way in which gender is deeply implicated in the daily interactions between individuals at a conscious and 
unconscious level, not just in the gender we 'do' but in the 'gender we think' (Gherardi, 1994:595).

The work of a number of feminist writers (see for example Benjamin 1988, Pringle 1989 and Wicks 1998) suggests that nurses are grappling with conflicting emotions and desires in terms of the doctor/nurse relationship and face a huge task in breaking free from the thinking that binds them to it. For Viv, Sarah and Maxine, this work takes place in silence, yet must continue within the context of an organisational culture which, in many ways, endorsed medical authority and dominance.

\section{Strategies}

In order to manage and negotiate their subordinate identity vis-à-vis their medical colleagues and to assert a more credible organisational image as board members, these nurses adopted a number of strategies (see also Drennan 2005 for similar findings in relation to Primary Care Groups). These strategies (which I have termed 'getting it right', 'achieving the right balance', 'self-presentation' and 'unassertiveness') emerged largely unsolicited throughout all the interviews. Such strategies both reflected and re-produced gendered power relations and identities, and illustrate one of the ways in which organisations are gendered as women and men make sense of and respond to gendered rules governing organisational behaviour.

Whilst these nurses' confidence appeared to grow over the period of fieldwork (three years), the study data suggest that the use of strategies continued throughout their time as board members. What becomes evident within these accounts is the precariousness of nursing identity in this policy context.

\section{Getting it right}

These nurses believed their credibility was not 'given' in a way that it was for other professional groups on the board, notably GP members. They felt they had to work hard to be seen as credible and could not assume equality with their colleagues - a situation Smith et al. (2000:87) also highlight in their evaluation of PCGs where nurses spoke of having to 'prove themselves capable'.

One of the most common strategies for dealing with their marginal status vis-à-vis their medical colleagues was to make sure they were as informed as possible and that whatever they said was accurate and relevant - they had to 'get it right' and be at their best:

Claire: We can be seen to have views, but whether those views are actually going to be listened to, this is where we have got to work at it because Rose and I have both learned that we have got to be absolutely one hundred per cent certain of our facts, so we have to do our homework properly before we bring anything up at the board meeting, whereas the GPs seem to be able to get away with a bit more, um, vague debate.

Maxine: It's okay for GPs to admit they don't know anything, but nurses have got to know everything; you don't want to make a fool of yourself.

Claire's comments suggest nurses' credibility as board members was in doubt. Nurses also highlighted the wider consequences for their credibility in terms of their influence in the future, were they to fail to 'get it right': 
Kim: It took me a while to realise - if I wasn't a hundred per cent sure, not to say anything because it would be wasted and that would mean that perhaps in the future they would doubt other things I might have to say.

Debbie: I try not to say anything unless it's worth listening to, because there is a tremendous danger of being aware you're not saying anything and just finding something to say. And that would be a tremendous downfall.

Several important issues arise from the nurses' accounts: the amount of effort and energy expended by nurses in adopting this strategy; their belief that the GPs did not face the same dilemma; and the perceived precariousness of a nursing identity. The difficulties nurses have in asserting a credible organisational image are particularly acute, given they have to negotiate a set of relations which position them as subordinate as women and as nurses.

One of the consequences of this strategy was the relative silence of nurses - a recurrent theme in my fieldnotes. Even when the discussion at board meetings reflected, as I saw it, nursing concerns and priorities, for the most part, nurses seldom spoke. The following fieldnotes relate to my observation of a board meeting where the representative from social services (John) was arguing that the board's Health Improvement Plan - a key document which outlined the priorities for health improvement of the local population - did not take sufficient account of the impact of social factors:

John argued that there was too much focus on a disease/traditional, bio-medical approach to health improvement. 'I thought we had moved away from that'. What the board were suggesting went against the 'national move toward recognising the relevance of broader socio-economic factors'. Harry (GP board member) commented that it was hard for the board to know how to address the social determinants of health; 'how does the government imagine we can do anything about wealth and underlying causes like poverty? Could we say as much in the HIP?' Murmurs of agreement from other board members. John fell quiet after this. The atmosphere felt awkward. Neither board nurses (Rose and Claire) said anything. I was interested in this, given nurses' insistence that they brought a different, more holistic focus to the discussions, one which acknowledged the significance of social factors and challenged the traditional medical model of health (Fieldnotes: board meeting LHG 3, phase 1).

There were perhaps a number of reasons for Claire's and Rose's silence. Both nurses acknowledged during interview that they lacked confidence in operating at board level and questioned their perceived credibility as board members. The fact that others on the board disagreed with John may have made it difficult for them to challenge, particularly if, as they argued, they were not absolutely certain of their facts.

Linda, a district nurse, was one of the nurse participants whom I observed contributing to the debate at board meetings. However, as my fieldnotes below indicate, her comments were met with little or no response. On this occasion Linda was the only female board member present:

Gary (GP) and Paul (GP Chair) were discussing how, as an LHG, they might develop a working plan to tackle some of the priorities that the board felt were important. Linda, having previously suggested external facilitation to help them develop their plans, reiterated her suggestion. Again, this is ignored and no other members respond to this. 
Paul changed the subject and began talking about something else. For the third time Linda reiterated her suggestion re external facilitation. No comment from the other board members. Another GP - David - continued, addressing the General Manager, and suggested they review further plans once they had received feedback from the 'away-day'. At the end of the board meeting as everyone was milling around, Linda says to me 'there was a bit of Doctor:Nurse stuff going on here today'. She sounded annoyed yet resigned (Fieldnotes: board meeting LHG 5, phase 2).

Linda understood her experience in terms of her lack of credibility as a nurse board member, particularly compared to her GP colleagues.

\section{Achieving the right balance}

Nurses also believed they were treading a fine line between success and failure. The following extract outlines the way in which Kim experienced this dilemma as a board member:

How valuable they (the board) take you is how dominant and verbal you are around the table, often. And I think there is a very fine balance to that because you could be too verbal, which means, 'Oh God here she or he goes again' to, 'Oh well they haven't said anything for months now, all of a sudden where has this come from?' (Kim).

Whilst Kim infers these rules apply equally to men and women, the consequences of failing to achieve the right balance impacts on men and women differently, as the earlier comments from nurses suggest. Being 'dominant' and 'verbal' are qualities often associated with male conversational behaviour (Katila and Merilainen 1999) and Kim identifies them as important if she wants to be seen as a valuable board member. She describes how she has to get the right balance - as a woman and nurse being seen to be 'too verbal' might jeopardise her credibility as a board member, but staying silent might risk Kim being viewed as having nothing important to say. It would also reinforce stereotypical views of women as passive and reticent.

Kate also highlights what she sees as the dilemma faced by nurses as they balance the conflicting demands of assertiveness and deference, and struggle to get their voices heard:

You want to be able to contribute and give your opinions, but what you don't want to do is become aggressive then, and defensive either, do you? You want to be able to assert yourself and be credible with that, don't you? Which hopefully I can do ... but I recognise there is a burden in doing that. I think you play a game (Kate).

More generally, these extracts illustrate the way individuals make sense of and respond to the (unspoken) gendered rules governing organisational behaviour (Acker 1992). Nurses' experiences suggest that in their attempts to create a positive credible organisational image, women tread a fine line between success and failure. Their presence as Other/outsider has to be carefully negotiated, a task for which they hold themselves responsible (Marshall 1984, Gherardi 1994). As Fournier and Kelemen (2001) comment in relation to their work on women managers:

The ambivalent effects of individual and collective strategies bear witness to the delicate balancing acts women have to perform to reconcile the tensions present in their dualistic position as 'women' and as 'competent managers' (2001: 272). 
The employment of strategies, however, is particularly problematic for nurses. It is 'femaleness' which requires 'management' (Sheppard 1989:144), but given the close cultural links between femininity and nursing, nurses face an especially onerous task in managing their identity and being seen as credible organisational members. Nurses are on the board precisely because they are nurses. In this context, their occupational identity, with its negative, gendered associations, is hard to escape. What seems clear is that a great deal of effort and forethought is needed to manage credibility in an organisational culture in which nurses and women are in many ways incredible (Hall 1989).

\section{Self-presentation}

The issue of presentation and in particular what they wore to board meetings emerged as an important strategy in managing what nurses perceived as their devalued identity. Sarah, Rose, and Viv said they would not wear a uniform to the LHG meetings. On each occasion, I had asked them whether they were conscious of their identity as a nurse when attending LHG meetings:

Viv: Not in the slightest bit conscious because I'm not in uniform ... If I was in uniform I think I would be labelled as 'Oh, there's the nurse'. I look forward perhaps to the day when I don't have to rush from work (to change). I think I would make every effort not to be in uniform.

Rose: No I'm just a member there. I think it would be different if I went in uniform. I've never gone in uniform... I think if I was there (in uniform) I would stand out like a sore thumb. You know, that nurse would be there wouldn't she?

Sarah: No ... I would not do it (attend a meeting in uniform) I don't care if I was late - I would go home and change to be on an equal level ... it's something I feel very strongly about... I will always get changed. And I will always try and dress as smartly as I can. I think it gives you more confidence to do that. I definitely feel far more sort of 'yes, I am a nurse, a humble nurse' (if in uniform) so I wouldn't do that. I don't know if [wearing a uniform] would have the opposite effect for the other members... but it's the GPs I want to be up there with.

Their accounts suggest that nurses' uniform is of great symbolic importance. The uniform signifies a range of meanings, including service, care, compassion, obedience and femininity attributes that nurses perhaps felt would detract from their credibility and status as board members.

The decision not to wear a uniform reflects nurses' response to the prevailing organisational culture within which they perceived themselves to occupy a marginal and devalued position. In wearing their own (smart) clothes, they create the "correct gendered persona' (Acker 1992: 253) and express 'a more masculine, instrumental relation to the body' (Pringle 1992: 177). Such gender management is significant for it illustrates the way in which daily interactions and the 'internal mental work of individuals' (Acker 1992: 253) reflects and reinforces the gendering of individuals and relations and with that, the organisational culture. 


\section{Unassertiveness}

My observation of meetings also suggested that when nurses did contribute, their behaviour often indicated a lack of assertiveness, and this too can be understood as a strategy.

Whilst observing a board meeting, I noticed Becky would always ask permission to speak. She would raise her hand to attract the Chair's attention then ask, 'Do you mind?' My fieldnotes at the time indicate I found this surprising. No one else asked for permission to speak. On another occasion, an LHG board were discussing their Health Improvement Programme. Linda, one of the nurses, sought clarification on a point identified in the programme as the 'integration of primary care and secondary care nursing'. Fieldnotes describe Linda's body language and the way she appeared when she spoke:

Linda appeared nervous - slipping one shoulder down, giggling, slightly apologetic, head on the side (Observation: board meeting LHG 5, Phase 2).

In identifying what appears to have been an oversight in the plan, Linda can be seen to have made a challenge and her behaviour indicates she felt uncomfortable about this. She tries to make herself physically smaller - less threatening; her actions reflect the precariousness of her identity as a legitimate and competent board member.

The significance of women's unassertiveness, as exemplified by Becky and Linda, is highlighted by a number of authors (see for example Gherardi 1995, Katila and Merilainen 1999, Fournier and Kelemen 2001). Gheradi 1995 understands such behaviour in terms of the on-going remedial work undertaken by women as they negotiate their displaced presence within male defined organisational culture. Asking permission to speak, apologising for doing so, and undermining the importance of what they have to say, are all strategies that women use to manage their status as 'outsider'. For Gherardi,

... women's lack of assertive style can be interpreted as a ritual that repairs the offence caused by the infringement of the symbolic order of gender when they speak (1995: 141).

Nurses invested an enormous amount of time and effort in their attempt to successfully pass as competent and credible organisational members. This work was considered essential by nurses if they were to influence decision making and to play a more active part in helping to shape and determine health policy.

\section{Nurses as outsiders}

In their attempts to overcome their position as outsider, nurses drew upon a variety of strategies, and continued to do so for the duration of their time as board members. The strategies discussed in this paper illustrate the remedial work (Gherardi 1995) carried out by nurses as they balance the conflicting demands and ideologies of their identity as nurses and women with their identity as competent board members.

Significantly, this gender management occurs with reference to the prevailing set of maledefined norms and expectations (Sheppard 1989). Most commonly, nurses attempted to blend in to the organisational culture, giving detailed attention to dress, self-presentation and behaviour. At the same time, strategies such as these shore up existing gender power relations and contribute to the gendering of organisational culture. 


\section{Conclusion}

This paper explores the policy-making role of nurses, focusing in particular on the way in which they experienced and made sense of their identity as nurses in the context of medical power and the doctor/nurse relationship. Nurses believed their contribution to the board and their ability to influence policy and decision making was limited by medical dominance. In response to their lack of power and subordinate status they employed a number of strategies that reflected and re-produced gendered identities and relations of power on the board.

Drawing on feminist theory to explore the way in which nurses feel about, construct, and negotiate the doctor/nurse relationship this paper builds on work which highlights the critical role of gender in this relationship (Porter 1995, Wicks 1998, Davies 2003), and helps to illuminate the processes whereby gendered patterns of dominance and subordination are recreated and sustained at an individual and structural level. Whilst supporting the basic premise of writers who question the necessarily oppressive and hierarchical nature of the doctor/nurse relationship, and point to ways in which this relationship is being undermined (Hughes 1988, Porter 1995, Svensson 1996, Allen 1997, 2001, Wicks 1998), it is important to acknowledge those experiences of nurses which suggest the relationship continues to exert a powerful influence in terms of nurses' daily working lives (Davies 2003).

More broadly, this paper contributes to an understanding of the gendering of organisational culture and the ways in which this process is re-created daily through the ongoing interactions, relations and strategising of women and men (Acker 1992).

The findings raise questions about the wider impact of gender upon nurses' organisational lives as they attempt to influence healthcare and decision making at the clinical, managerial and strategic level.

The experiences of nurses within the NHS policy-making arena appears to be an underresearched area, and one that has received relatively little attention. This is despite the importance and value of nursing and nurses in shaping health policy (Burdett Trust 2006, RCN/National Voices 2009) and continuing concerns regarding the absence of a nursing voice from the policy making arena (Queens Nursing Institute 2006, RCN/National Voices 2009).

Government policy identifies clinicians, including nurses, as having a key leadership role in shaping and driving forward policy reform and quality improvement within the NHS (Darzi 2008) and there have been renewed calls for nurses to have a powerful voice at all levels of the healthcare system, including policy making (Maben 2008). The challenges facing nurses need to be seen in the context of gender. An understanding of the way in which gender power relations operating at the micro- and macro-level serve to diminish and silence women (Acker 1992) is needed, if some of the obstacles nurses face in their attempts to influence and contribute to health policy are to be addressed.

Address for correspondence: Alison Hughes, School of Health and Social Care, University of the West of England, Glenside Campus, Blackberry Hill, Stapleton, Bristol, BS16 1DD e-mail: Alison2.Hughes@uwe.ac.uk

\section{Acknowledgements}

I would like to acknowledge all those who took part in the study for giving their time and thoughts so generously. My particular thanks to Katie Featherstone, Davina Allen and Anne Williams (School of 
Nursing and Midwifery Studies, Cardiff University) and to the anonymous reviewers for their helpful comments on earlier drafts of this paper. The research on which this paper is based was supported by a University of Wales Swansea studentship.

\section{Note}

1 For the purposes of this paper the term 'nurses' includes midwives, health visitors and community psychiatric nurses, district and practice nurses - all of whom were represented on LHG boards.

\section{References}

Acker, J. (1991) Hierarchies, jobs, bodies: a theory of gendered organizations. In Lorber, J. and Farrell, S.A. (eds) The Social Construction of Gender. London: Sage.

Acker, J. (1992) Gendering organisational theory. In Mills, A. and Tancred, P. (eds) Gendering Organisational Analysis. London: Sage.

Allen, D. (1997) The nursing-medical boundary: a negotiated order? Sociology of Health and Illness, 19, 4, 498-520.

Allen, D. (2001) The Changing Shape of Nursing Practice. London: Routledge.

Antrobus, S. (1998) Board and lodgings, Nursing Times, 94, 50, 50-2, 16 December.

Benjamin, J. (1988) The Bonds of Love: Psychoanalysis, feminism, and the Problem of Domination. New York: Pantheon Books.

Bogdewic, S. (1992) Participant observation. In Crabtree, B. and Millar, W. (eds) Doing Qualitative Research. Newbury Park, CA: Sage.

Brewer, J. D. (2000) Ethnography. Buckingham: Open University Press.

Burdett Trust for Nursing (2006) Who Cares, Wins: Leadership and the Business of Caring. London: Burdett Trust for Nursing.

Coffey, A. and Atkinson, P. (1996) Making Sense of Qualitative Data: Complementary Research Strategies. Thousand, Oaks CA: Sage.

Darzi, A (2008) High Quality Care for All: NHS Next Stage Review Final Report. London: Department of Health.

Davies, C. (1995) Gender and the Professional Predicament in Nursing. Buckingham: Open University Press.

Davies, K. (2003) The body and doing gender: the relations between doctors and nurses in hospital work, Sociology of Health and Illness, 25, 7, 720-42.

Department of Health (1994) Building a Stronger Team: the Nursing Contribution to Purchasing. Leeds: NHS Executive.

Department of Health (1997) The New NHS: Modern, Dependable. London: The Stationery Office.

Department of Health (2008) NHS Next Stage Review: our Vision for Primary and Community Care. London: Department of Health.

Dowswell, T., Wilkin, D. and Banks-Smith, J. (2002) Nurses and English primary care groups: their experiences and perceived influence on policy development, Journal of Advanced Nursing, $37,1,35-42$.

Drennan, V (2005) Clinicians as Leaders in local Governance Bodies: the Case of Primary Care Groups. Unpublished PhD thesis. University of London, Kings College.

Exworthy, M (2001) Primary Care in the UK: understanding the dynamics of devolution, Health and Social Care in the Community, 9, 5, 266-78.

Fournier, V. and Kelemen, M. (2001) The crafting of community: recoupling discourses of management and womanhood, Gender, Work and Organisation, 8, 3, 267-90.

Gamarnikow, E. (1978) Sexual division of labour: the case of nursing. In Kuhn, A. and Wolpe, A.M. (eds) Feminism and Materialism. London: Routledge and Kegan Paul. 
Gherardi (1994) The gender we think, the gender we do in our everyday organisational lives, Human Relations (special issue), 47, 6, 591-610.

Gherardi, S. (1995) Gender, Symbolism and Organisational Cultures. London: Sage.

Graham, H. (1983) Caring: a labour of love. In Finch, J. and Groves, D. (eds) A Labour of Love: Women, Work and Caring. London: Routledge and Kegan Paul.

Hall, M. (1989) Private experiences in the public domain: lesbians in organizations. In Sheppard, D., Hearn, J., Tancred-Sheriff, P. and Burrell, G. (eds) The Sexuality of Organization. London: Sage.

Hammersley, M. and Atkinson, P. (1995) Ethnography: Principles in Practice. London: Routledge.

Hughes, D. (1988) When nurse knows best: some aspects of nurse/doctor interaction in a casualty department, Sociology of Health and Illness, 10, 1, 1-22.

Hughes, A (2005) The Experiences of Nurses on LHG Boards in Wales: a Gendered Analysis. Unpublished PhD thesis. University of Wales Swansea.

Katila, S. and Merilainen, S. (1999) A serious researcher or just another nice girl?: doing gender in a male-dominated scientific community, Gender, Work and Organization, 6, 3, 163-73.

Kaufman, G. (2002) Investigating the nursing contribution to commissioning in primary healthcare, Journal of Nursing Management, 10, 2, 83-94.

Kerr, N. (1982) The narcissistic fit between medicine and nursing. In Muff, J.E. (ed.) Socialization, Sexism and Stereotyping. Illinois: Waveland Press Inc.

King's Fund College (1993) The Professional Nursing Contribution to Purchasing. London: King's Fund.

Lofland, J. and Lofland, L. (1984) Analyzing Social Settings: a Guide to Qualitative Observation and Analysis. Belmont, CA: Wadsworth.

Maben, J (2008) Nurses in Society: Starting the Debate. London: King's College.

Marshall, J. (1984) Women Managers: Travellers in a Male World. Chichester: Wiley.

Maynard, M. and Purvis, J. (1994) Researching Women's Lives from a Feminist Perspective. London: Taylor and Francis.

Mayor, S. (1998) Primary Care Groups - friend or foe? Practice Nurse, 15, 10, 578-81.

Mays, N. and Pope, C. (1995) Rigour and qualitative research, British Medical Journal, 311, $109-12$.

Mills, A and Tancred, P. (1992) Gendering Organisational Analysis. London: Sage.

Porter, S. (1995) Nursing's Relationship with Medicine: a Critical Realist Ethnography. Aldershot: Avebury.

Pringle, R. (1989) Secretaries Talk: Sexuality, Power and Work. London: Verso.

Pringle, R. (1992) What is a secretary? In McDowell, L. and Pringle, R. (eds) Defining Women: Social Institutions and Gender Divisions. Cambridge: Polity in association with The Open University.

Queens Nursing Institute (2006) Vision and Values - a Call for Action on Community Nursing. London: Queens Nursing Institute.

RCN (1999) The New Local Health Groups: the Knowledge and Skills Nurses Need to Make them a Real Success. London: RCN.

RCN/National Voices (2009) Local Healthcare Commissioning: Grassroots Involvement? London: $\mathrm{RCN} /$ National voices.

Regen, E., Smith, J., Goodwin, N., McLeod, H. and Shapiro, J. (2001) Passing on the Baton: Final Report of a National Evaluation of Primary Care Groups and Trusts. Birmingham: Birmingham, Health Services Management Centre, University of Birmingham.

Reverby, S. (1987) Ordered to Care: the Dilemma of American Nursing 1850-1945. Cambridge: Cambridge University Press.

Robinson, J. (1992) Introduction: Beginning the study of nursing policy. In Gray, A., Elkan, R. and Robinson, J. (eds) Policy Issues in Nursing. Buckingham: Open University Press.

Sheppard, D. (1989) Organizations, power and sexuality: the image and self-image of women managers. In Sheppard, D., Hearn, J., Tancred-Sheriff, P. and Burrell, G. (eds) The Sexuality of Organization. London: Sage. 
Smith, J., Regen, E., Goodwin, N., McLeod, H. and Shapiro, J. (2000) Getting into their Stride: Interim Report of a National Evaluation of Primary Care Group. Birmingham: Birmingham, Health Services Management Centre, University of Birmingham.

Smith, J. (2000) Primary care groups: how are they shaping up? British Journal of Midwifery, 8, 2, $107-09$.

Smith, K., Dickson, M. and Sheaff, R. (1999) Second among equals, Nursing Times, 95, 13, 54-5, 31 March.

Speed, S and Luker, K (2006) Getting a visit: how district nurses and general practitioners 'organise' each other in primary care, Sociology of Health and Illness., 28, 7, 883-902.

Stanley, L. and Wise, S. (1993) Breaking Out again: feminist ontology and epistemology. London: Routledge.

Strauss, A. and Corbin, J. (1998) Grounded theory methodology: an overview. In Lincoln, Y. and Denzin, N. (eds) Strategies of Qualitative Inquiry. Thousand Oaks, CA: Sage.

Svensson, R. (1996) The interplay between doctors and nurses - a negotiated order perspective, Sociology of Health and Illness, 18, 3, 379-98.

Welsh Assembly Government (2008) Consultation Paper II: Delivering the new NHS for Wales. **?Cardiff: WAG.

Welsh Office (1998a) NHS Wales: Putting Patient's First. Cardiff, Welsh Office.

Welsh Office (1998b) Putting Patient's First: Establishing Local Health Groups. Cardiff, Welsh Office.

West, C. and Zimmerman, D.H. (1991) Doing gender. In Lorber, J. and Farrell, S.A. (eds) The Social Construction of Gender. London: Sage.

Wicks, D. (1998) Nurses and Doctors at Work: Rethinking Professional Boundaries. Buckingham: Open University Press.

Williams, A. (1993) Diversity and agreement in feminist ethnography, Sociology, 27, 4, 575-89. 


\section{Author Query Form}

\section{Journal: $\quad$ SHIL}

\section{Article: $\quad 1258$}

Dear Author,

During the copy-editing of your paper, the following queries arose. Please respond to these by marking up your proofs with the necessary changes/additions. Please write your answers on the query sheet if there is insufficient space on the page proofs. Please write clearly and follow the conventions shown on the attached corrections sheet. If returning the proof by fax do not write too close to the paper's edge. Please remember that illegible mark-ups may delay publication.

Many thanks for your assistance.

\begin{tabular}{|l|l|l|}
\hline $\begin{array}{l}\text { Query } \\
\text { reference }\end{array}$ & Query & Remarks \\
\hline 1 & $\begin{array}{l}\text { AUTHOR: Copy editor queried the fact that 'English } \\
\text { counterparts' were mentioned, but it was not made } \\
\text { clear how specific the study might be to Wales - please } \\
\text { check. }\end{array}$ & \\
\hline
\end{tabular}




\section{Please correct and return this set}

Please use the proof correction marks shown below for all alterations and corrections. If you wish to return your proof by fax you should ensure that all amendments are written clearly in dark ink and are made well within the page margins.

\begin{tabular}{|c|c|c|}
\hline Instruction to printer & Textual mark & Marginal mark \\
\hline Leave unchanged & ... under matter to remain & ( \\
\hline $\begin{array}{l}\text { Insert in text the matter } \\
\text { indicated in the margin }\end{array}$ & $h$ & $\begin{array}{l}\text { New matter followed by } \\
h \text { or } h \otimes\end{array}$ \\
\hline Delete & $\begin{array}{l}\text { I through single character, rule or underline } \\
\text { or }\end{array}$ & $\sigma$ or $\sigma / \otimes$ \\
\hline $\begin{array}{l}\text { Substitute character or } \\
\text { substitute part of one or } \\
\text { more word(s) }\end{array}$ & / through letter or & $\begin{array}{l}\text { new character / or } \\
\text { new characters / }\end{array}$ \\
\hline Change to italics & — under matter to be changed & $\leftarrow$ \\
\hline Change to capitals & $\equiv$ under matter to be changed & $\equiv$ \\
\hline Change to small capitals & $=$ under matter to be changed & $=$ \\
\hline Change to bold type & $\sim$ under matter to be changed & $\sim$ \\
\hline Change to bold italic & $\approx$ under matter to be changed & $\underline{s i n}$ \\
\hline Change to lower case & Encircle matter to be changed & $\not$ \\
\hline Change italic to upright type & (As above) & \\
\hline Change bold to non-bold type & (As above) & \\
\hline Insert 'superior' character & $\begin{array}{l}\text { I through character or } \\
K \text { where required }\end{array}$ & $\begin{array}{l}y^{\prime} \text { or } y \\
\text { under character } \\
\text { e.g. } y^{2} \text { or } y^{2}\end{array}$ \\
\hline Insert 'inferior' character & (As above) & $\begin{array}{l}\text { L } \\
\text { over character } \\
\text { e.g. } \hat{\imath}\end{array}$ \\
\hline Insert full stop & (As above) & $\odot$ \\
\hline Insert comma & (As above) & , \\
\hline Insert single quotation marks & (As above) & $\begin{array}{l}\dot{y} \text { or } \dot{X} \text { and/or } \\
\dot{y} \text { or } \dot{X}\end{array}$ \\
\hline Insert double quotation marks & (As above) & $\begin{array}{l}\ddot{y} \text { or } \ddot{y} \text { and/or } \\
\ddot{y} \text { or } \ddot{x}\end{array}$ \\
\hline Insert hyphen & (As above) & $1-1$ \\
\hline Start new paragraph & $\digamma$ & 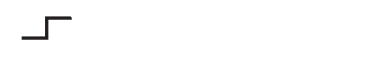 \\
\hline No new paragraph & $\infty$ & $\omega$ \\
\hline Transpose & $\sqcup$ & ᄃ \\
\hline Close up & linking $\bigcirc$ characters & \\
\hline $\begin{array}{l}\text { Insert or substitute space } \\
\text { between characters or words }\end{array}$ & $\begin{array}{l}\text { I through character or } \\
\Lambda \text { where required }\end{array}$ & \\
\hline $\begin{array}{l}\text { Reduce space between } \\
\text { characters or words }\end{array}$ & $\begin{array}{l}\text { between characters or } \\
\text { words affected }\end{array}$ & $\uparrow$ \\
\hline
\end{tabular}

